\title{
我国先进纤维材料产业发展战略研究
}

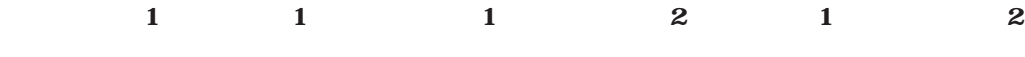 \\ (1. 中国纺织科学研究院有限公司, 北京 $100025 ； 2$. 东华大学材料科学与工程学院, 上海 201620)
}

\begin{abstract}
摘要: 我国化学纤维产量居全球首位, 是国民经济支柱产业, 当前化学纤维产业发展仍存在突出问题, 亟需加快提升先进纤 维材料产业的发展, 带动化学纤维产业和纺织行业的高质量发展。本文围绕化学纤维中的差别化功能纤维、高性能纤维、生 物基纤维三类先进纤维材料, 分析了我国先进纤维材料的发展现状、面临挑战以及发展趋势。在此基础上, 面向未来需求, 凝练了我国先进纤维材料产业今后发展的重点任务为突破关键核心技术形成标志性产品、提升智能制造水平、加强自主创新 能力建设、加强科技人才队伍建设。本文从加强产业发展战略研究、完善产业科技创新体系建设、加强科学技术的支撑与引 领作用、支持骨干企业国际化以及统筹发展等方面提出了发展建议, 以期为推动我国纤维材料产业高质量发展提供理论参考。 关键词: 差别化功能纤维; 高性能纤维; 生物基纤维; 产业发展
\end{abstract}

中图分类号: TB3 文献标识码: A

\section{Development Strategies for China's Advanced Fiber Materials Industry}

\author{
Qu Ximing ${ }^{1}$, Wang Ying ${ }^{1}$, Qiu Zhicheng ${ }^{1}$, Zhang Qinghua ${ }^{2}$, Li Xin ${ }^{1}$, Yu Jianyong ${ }^{2}$ \\ (1. China Textile Academy, Beijing 100025, China; 2. College of Materials Science and Engineering, Donghua University, \\ Shanghai 201620, China)
}

\begin{abstract}
China's chemical fiber volume ranks first in the world and is a pillar industry of the national economy. However, there are still prominent problems regarding the development of the chemical fiber industry and promoting the advanced fundamental fiber materials has become the key to the high-quality development of the chemical fiber and textile industries. This study focuses on three types of advanced fiber materials: differential fiber, high-performance fiber, and bio-based fiber. The status, challenges, and development trends of the advanced fiber materials in China are analyzed. On this basis, the key tasks for the future development of the advanced fiber materials are summarized, including developing key technologies to form representative products, improving the intelligent manufacturing level, strengthening the independent innovation capacity, and enhancing the training of scientific and technological talents. This study also proposes development suggestions from the aspects of industrial development strategy, scientific and technological innovation system, the role of science and technology, internationalization of key enterprises, and coordinated development, hoping to provide a theoretical reference for the high-quality development of China's fiber materials industry.
\end{abstract}

Keywords: differential fiber; high-performance fiber; bio-based fiber; industry development

收稿日期 : 2020-07-25; 修回日期 : 2020-09-10

通讯作者: 李金金, 中国纺织科学研究院有限公司研究员, 研究方向为先进纤维材料; E-mail: lixin@cta.com.cn

资助项目：中国工程院咨询项目 “新材料强国 2035 战略研究” (2018-ZD-03)

本刊网址：www.engineering.org.cn/ch/journal/sscae 


\section{一、前言}

我国是全球化学纤维产业链最为完整、品种 丰富、规模最大、产业配套最齐全的生产国、消费 国和出口国。化学纤维产品除应用于传统的纺织 服装、家居等消费品领域外，还广泛应用于交通运 输、环境保护、安全防护、土工建筑、医疗卫生、 航空、航天、国防军工等领域 [1]。我国化学纤维 产业的快速发展始于 20 世纪末期, 随着聚酯纤维 国产化技术与装备的不断突破，生产成本显著降 低, 产能高速增长, 2019 年我国化学纤维产量约为 $5.95 \times 10^{7} \mathrm{t}$, 约占全球化学纤维总产量的 $80 \%$ 。

目前, 我国化学纤维产业发展面临一些突出问 题, 如同质化现象严重导致产品附加值低, 高性能 纤维的品质和成本不具有市场竞争优势，生物基纤 维产品生产规模小、成本高, 尚不能实现对石油基 纤维产品的有效替代。当前, 在国际纺织产业再分 工的背景下，这些问题制约着我国化学纤维产业的 可持续发展，难以形成产业的国际竞争优势。

先进基础纤维材料（简称为先进纤维材料）指 可实现规模化生产和广泛应用的，具有以下一个或 多个特征的材料：物理机械性能和品质良好；在保 证物理机械性能满足应用的同时，可通过物理、化 学手段赋予材料新功能; 可实现全生命周期绿色化 水平提升; 通过数字化、柔性化和智能化制造过程 可提升纤维材料的制造效率和产品品质, 显著降低 能耗、物耗。

本文围绕先进纤维材料中最重要的差别化功能 纤维、高性能纤维、生物基纤维品种, 分析我国先 进纤维材料产业的发展现状、面临挑战以及未来的 发展趋势, 总结今后发展的重点任务, 提出发展建 议, 为产业和企业的发展提供参考。

\section{二、我国先进纤维材料产业发展现状}

\section{（一）差别化功能纤维}

近年来, 我国化学纤维生产产能持续快速扩张, 产业结构性过剩问题凸显, 常规化学纤维品种同质 化竞争激烈、附加值低, 因此, 基于现有产能条件 下的纤维差别化、功能化生产成为化学纤维产业结 构调整和产业升级的关键。

功能纤维是一个总体概念, 指纤维自身具备特
定的性质和功能, 并由此赋予纺织产品新的性质和 功能。按照纤维自身的性质, 功能纤维可以分为两 类: 一类为差别化功能纤维, 是在聚酯纤维、聚酰 胺纤维、再生纤维素纤维等常规化学纤维制备过程 中, 通过综合运用分子改性、功能组分添加、特种 纺丝成形以及纤维后处理等一种或几种方式制备而 成。与常规化学纤维相比, 这类纤维可以显著改善 或增加纤维的性能和功能。另一类是本征功能纤维, 即纤维本质上具有特定的性能或功能, 这些纤维是 聚合物通过熔体纺丝或溶液纺丝制备而成的, 如具 有高弹性的氨纶等。

经过重点推进, 我国差别化功能纤维发展取得 了显著成绩, 建立起产业链完整、品种齐全的功能 纤维产业体系, 与日本、美国和欧盟等发达国家和 地区的差距明显缩小 [2]。2017 年, 我国差别化功 能纤维的产量约为 $1 \times 10^{7} \mathrm{t}$, 多为原液着色纤维、阳 离子染料可染纤维、高性能聚酯与聚酰胺工业丝、 低熔点复合短纤维等附加值相对较低的常规功能纤 维品种, 而以超仿真纤维、抑菌纤维、阻燃纤维、 远红外纤维等为代表的高附加值功能纤维品种占比 相对较低。差别化功能纤维生产工艺及技术还不够 完善, 产品品质不高, 难以大批量用于高端面料和 制品。

\section{（二）高性能纤维}

我国高性能纤维领域发展的重点是碳纤维、芳 纶、超高分子量聚乙烯 (UHMWPE) 纤维、聚酰 亚胺 (PI) 纤维和聚苯硫醚 (PPS) 纤维等。

\section{1. 碳纤维}

在过去 10 年间, 我国碳纤维产业进入了蓬勃 发展时期, 实现了“从无到有” 的突破, 工艺技术 不断提升, 工艺装备不断优化，应用领域不断拓展。 2019 年, 国内聚丙烯腈（PAN）基碳纤维快速发 展, 产量约为 $1.2 \times 10^{4} \mathrm{t}$; 国内消费量超过 $3.7 \times 10^{4} \mathrm{t}$, 增长约 20\% [3], 广泛应用于风电叶片、建筑补强、 压力容器等领域, 在航空、航天、电子电器等领域 也逐渐应用。

\section{2. 芳纶}

近年来我国对位芳纶发展迅速, 多家企业的产 业化技术取得突破，实现了批量生产。2019 年，国 内对位芳纶产量实现小幅增长, 约为 $2.8 \times 10^{3} \mathrm{t}$; 间 位芳纶产量约为 $1.1 \times 10^{4} \mathrm{t}$ [3], 总体达到国际先进水 
平。目前国产芳纶产品主要用于高温过滤、防护、 密封等材料中。与国外产品相比, 国产芳纶产品在 航空、航天、国防军工等高端领域的应用尚缺乏竞 争力。

\section{UHMWPE 纤维}

近年来, 我国制备 UHMWPE 纤维技术发展迅 速, 产品质量大幅提升, 性能指标达到国际先进水 平, 个别指标达到国际领先水平。国外对高端纤维 制品也多采取出口限制措施。国内目前约有 30 家 企业生产高强高模聚乙烯纤维, 2019 年的产量为 $2.3 \times 10^{4} \mathrm{t}[3]$, 产能达到千吨级的企业数量不多。

\section{PI 纤维}

近年来, 我国 PI 纤维产业得到迅猛发展, 相 关科研机构也开始重视 PI 纤维的研发。我国耐高温 型 PI 纤维已商品化生产; 高强高模 PI 纤维完成小 试试验, 断裂强度达到 $3.5 \mathrm{GPa}$, 模量为 $130 \mathrm{GPa}$, 总体达到国际先进水平。

\section{PPS 纤维}

袋式除尘技术的快速发展带动了国内纤维级 PPS 树脂生产企业的发展。2019 年国内 PPS 纤维产 量约为 $5.5 \times 10^{3} \mathrm{t}$ [3], 产品规格仍多集中在 $2.0 \mathrm{dtex}$, 主要应用在滤料行业, 总体需求保持稳定。近年来, 纤维级 PPS 树脂合成产业化技术不断优化, 成本逐 渐降低, 有望进一步提高产量, 推动国产品种的市 场化应用。

\section{（三）生物基纤维}

生物基纤维指以生物质为原料, 或含有生物质 来源的单体、以生物技术制备的单体的聚合物纤维, 主要包括莱赛尔纤维、聚乳酸纤维、生物基聚酯纤 维和生物基聚酰胺纤维。我国生物基纤维总体上处 于产业化初期。

中国纺织科学研究院的全国产化技术 $1.5 \times 10^{4} \mathrm{t} / \mathrm{a}$ 莱赛尔纤维生产线于 2016 年年底全线贯通。2019年, 国内有 3 家企业拥有万吨级莱赛尔纤维生产线, 单 线设计产能均为 $3.0 \times 10^{4} \mathrm{t} / \mathrm{a}$, 与奥地利兰精公司已 达到的 $6.7 \times 10^{4} \mathrm{t} / \mathrm{a}$ 单线产能相比, 尚需进一步的技 术升级。

我国在 2000 年前后开始研发聚乳酸生产技术, 目前我国聚乳酸产业正处于工业化起步阶段。目前, 多家国内企业建设了聚乳酸连续聚合产业化生产 线, 同时也实现了长丝、短纤维、纺粘非织造布等
产品的生产, 多用于一次性卫材、农业、服装和家 纺等领域。目前, 由于原料丙交酯的国产化水平不 足, 聚乳酸产业发展受到的限制较大。

国内企业自 2010 年起突破了生物基 1,3-丙二 醇 (PDO) 的关键技术, 实现了 PDO 万吨级生产; 在聚对苯二甲酸丙二醇酯 (PTT) 聚合方面通过技 术攻关, 初步实现了产业化, 正在攻克大容量连续 聚合、熔体直纺等关键技术, 有望实现我国生物基 PTT 纤维的稳定化、规模化生产与应用 [4]。

国内在 2010 年前后启动了聚酰胺 56 (PA56) 纤维材料的相关研究。凯赛生物公司实现了生物 基 1,5-戊二胺和 PA56 的中试, 处于世界先进水平。 我国目前正在建设的产能为 $5 \times 10^{4} \mathrm{t} / \mathrm{a}$ 生物基 1,5 - 戊 二胺及 $1 \times 10^{5} \mathrm{t} / \mathrm{a}$ 生物基 PA56 生产基地, 开发新的 应用领域成为量大面广应用的关键。

\section{三、我国先进纤维材料产业发展面临的挑战}

\section{（一）差别化功能纤维}

我国差别化功能纤维总体上处于产业快速发展 的初期, 当前, 产业发展面临一些迫切需要解决的 问题。纤维生产装备研制和工艺研发脱节, 生产装 备老旧, 导致在差别化功能纤维生产过程中无法对 反应过程、成型过程实现有效控制, 严重制约了纤 维的高品质化发展。

制约我国功能纤维产业发展的另一个重要原 因是缺乏完善的性能评价与品质检测方法及标准体 系, 使产业发展缺乏有效的规范与指导。功能纤维 性能评价与品质检测的方法及标准体系的建立, 可 统一规范行业的有序发展避免无序竞争, 指导生产 企业优化产品的功能指标与产品品质。

\section{（二）高性能纤维}

在碳纤维材料方面, 我国的碳纤维材料产品大 多处于试运行、少量装机阶段, 与产业下游的合作 仍需加强。产业应用端开发的不充分导致了大量碳 纤维生产企业产能虚高, 企业运营压力较大。未来 碳纤维生产企业需进一步加强与产业应用端的 “产 研” 联动, 抓住市场机遇, 为国产碳纤维产业的发 展寻找突破。

在芳纶纤维方面, 我国间位芳纶产业的发展尚 处于起步阶段, 制造技术落后于发达国家, 难以实 
现高性能间位芳纶产品的高速、稳定生产。我国对 位芳纶产品初步实现产业化, 部分差异化产品的核 心技术仍未完全掌握, 如高强型、高模型、可染色 纤维等。

在 UHMWPE 纤维方面, 产业规模化程度低, 国内单线产能多在 $200 \mathrm{t} / \mathrm{a}$, 而国外单条生产线的产 能普遍在 $500 \mathrm{t} / \mathrm{a}$ 左右。为提高总产能, 国内生产企 业不得不增加生产线，造成投资成本高、生产效率 低、能耗高, 规模化生产较难实现。

在 PI 纤维方面, 国内 PI 纤维的性能已经达到 世界先进水平，但由于国内原料生产企业产品质量 参差不齐、价格较高, 导致 PI 纤维价格高于芳纶, 限制了下游企业的应用。另外, 我国 PI 纤维产品 的精细化程度不够, 品种少, 多用于军工领域, 民 用领域应用较少。

另外, 国内 PPS 改性技术开发起步较晚, 以中 小型企业居多，在产品品质管理和成本控制上与 国外企业存在差距。在国外 PPS 改性企业已经长 期占据国际市场的前提下，国内企业后期进入遇 到的阻力较大。

\section{（三）生物基纤维}

我国生物基纤维的发展基本处于起步阶段, 在 技术、装备、基础研究等方面与国外存在一定差距, 尚未形成良性供应链体系。目前, 生物基纤维生产 成本高、产品市场竞争力弱, 制约着产业的良性发 展, 特别是在当前低油价时代, 无法形成与石油基 纤维的竞争优势。

生物基纤维及其原料需要的基因技术、工业微 生物技术、生化技术基础薄弱, 多数品种处于小试 研究阶段, 具有自主知识产权的原料品种少, 纤维 及原料制备难度大、成本高。总之，我国在核心技 术、关键设备、关键原料方面与发达国家相比差距 仍然较大，产业技术水平偏低。

\section{四、我国先进纤维材料产业发展趋势}

\section{（一）差别化功能纤维}

高品质、高功能、低消耗、低排放是差别化功 能纤维产业化技术发展的方向。高品质指纤维本身 的不匀率低, 纤维在纺织、染整、涂层、复合加工 过程及纺织品使用过程中性能/功能稳定。高功能
指纤维材料基本的物理性能（强度、模量、弹性、 线密度等）与改善纺织品舒适性、防护性等密切相 关的性能 / 功能, 与显著提升纺织品和服装的智能 化密切相关的性能/功能。低消耗和低排放指纤维 材料从原料获取、纤维制造、应用到废弃产品回收 处理的全生命周期的物耗、能耗、有害物质排放、 废弃物垃圾及其处理成本的显著降低。

面向量大面广的需求, 超仿真纤维、低温染色 纤维、吸湿速干纤维、低熔点纤维等是差别化功能 纤维的重点品种。面向作战、特种防护、智能纺织 品等特种需求, 阻燃纤维、导电纤维、抑菌纤维、 高耐磨纤维等也是重点品种。

\section{（二）高性能纤维}

碳纤维的低成本化和高性能化是今后的发展趋 势, 通过开拓新型的、廉价的、可替代的碳纤维前 躯体以及开发新的工艺方法, 不断降低碳纤维生产 成本 [5]。

对位芳纶的发展趋势是通过技术先进性推进应 用产品升级换代, 开发差异化产品, 满足高端领域 应用要求。目前国产对位芳纶主要应用于高温过滤、 防护材料、密封材料等领域, 在对于力学性能要求 较高的轮胎、橡胶制品、电子通信器材等应用领域, 尤其是在航空、航天及国防军工等高端领域与国外 产品相比尚缺乏竞争力。

UHMWPE 纤维的发展趋势是开发高端领域用 的差异化产品。高端应用领域的 UHMWPE 纤维一 直由帝斯曼（DSM）公司引领，已开发的具有更高 力学性能的产品, 强度为 $40 \mathrm{cN} / \mathrm{dtex}$ 以上; 耐蠕变 型纤维已用于高强抗蠕变绳索; 最近又成功研发 了超低蠕变型纤维, 在标准条件下长期使用蠕变 伸长仅为 $0.5 \%$ 左右, 成功用于海上采油平台的系 泊缆绳。

PI 纤维的发展趋势为降低生产成本, 主要途径 有：一是在单体合成及聚合方法上寻找出路; 二是 利用 PI 纤维的高性能改进其他聚合物以发展一类 新的性能比芳香 PI 纤维稍低, 但却高于被改性聚 合物的新品种。例如, 充分发挥 PI 纤维本质阻燃 特征, 制备 PI / 黏胶高阻燃复合纤维。

PPS 纤维的发展趋势是提高纤维品质, 开发差 异化产品。目前我国的 PPS 纤维产品较为单一, 主 要生产常规短纤维产品, 纤维的细度、卷曲率以及 
干热收缩率等指标与日本东丽公司的产品相比存在 较大差距。国内细旦纤维 ( $<1.0 \mathrm{dtex})$ 、异形截面纤 维、高卷曲纤维等差异化 PPS 纤维产品尚没有实现 产业化。

\section{（三）生物基纤维}

莱赛尔纤维是典型的绿色纤维产品, 具有黏胶 纤维无法比拟的性能优势。莱赛尔纤维未来的发展 重点是通过技术改进实现产品的高品质、低成本和 广泛应用; 同时, 莱赛尔功能纤维也将得到快速发 展, 并展现出较高附加值, 如阻燃纤维、抗起球纤 维等品种 [6]。

聚乳酸纤维耐热性较差, 给后续的纺织、染整 加工和服装尉惣带来困难, 因此提高聚乳酸纤维耐 热性是今后的发展趋势, 需要开发 $\mathrm{D}$ 型聚乳酸以及 立体异构复合物的制备技术。

近年来, 国际上 PTT 除了用于制备纤维以外, 主要应用于工程塑料、薄膜领域。

生物基 PA56 纤维的关键原料戊二胺国内已取 得产业化突破, 开发了包括生物法制备成二胺和生 物基聚酰胺等国内外领先的产业化技术和装备, 建 立了国内外首套生物基聚酰胺产业化中试试验生 产线并成功运行。PA56 聚合的重点是突破连续化、 规模化生产并实现熔体直纺, 同时拓展下游新应用 领域。

\section{五、我国先进纤维材料产业发展的重点任务}

我国先进纤维材料产业发展的总体目标是建成 布局合理、充满活力的产业技术创新体系, 形成一 批具有自主知识产权的原始创新成果, 建立科技成 果高效率转化机制, 涌现一批具有国际影响力的实 验室和人才队伍, 形成纤维材料产业持久的创新能 力, 从而培育出有国际竞争力的骨干企业, 从根本 上解决结构性产能过剩, 提升我国中高端产品占比, 使纤维材料的绿色化、智能化水平达到国际领先, 带动整个纺织产业总体进入价值链中高端。

\section{（一）突破关键核心技术形成标志性产品}

\section{1. 超仿真纤维}

以超仿棉纤维、超仿毛纤维等为重点, 突破新 型分子结构设计与可控聚合技术、功能粉体高比例
精确添加与稳定分散技术、非重金属催化体系活性 调控与应用技术、高异形度细旦纤维截面精确控制 技术、多异多重复合纤维一步法高度均混纤加工技 术等关键技术, 显著提升超仿真纤维的服用舒适性, 开发出高品质超仿真纤维。

\section{2. 阻燃纤维}

以聚酯纤维、PA 纤维和再生纤维素纤维为重 点, 突破环境友好阻燃剂分子结构设计与绿色制造 技术、长效阻燃纤维柔性化高效制备技术、阻燃纤 维纺织品设计与加工整理技术等, 开发出具有高极 限氧指数、低发烟量、抗熔滴的生态长效阻燃纤维, 实现高品质阻燃纤维的大规模市场应用。

\section{3. 导电纤维}

以聚酯纤维、PA 纤维和 PAN 纤维为重点, 突 破导电功能粉体的超细化与窄分布加工技术、功能 粉体表面修饰技术、易流动与抗团聚导电母粒制备 技术、高固含量纺丝熔体复合成型高效纺丝技术、 高金属离子负载纤维制备技术等, 提升导电纤维的 导电性, 开发出具有低电阻值的导电纤维以满足智 能穿戴应用的需求。

\section{4. 高性能工业丝}

以聚酯纤维、PA 纤维为重点, 突破高黏熔体 改性技术、高均匀性熔体制备技术、高分子量树脂 纺丝工艺技术及其专用助剂、高黏度熔体输送技术、 黏度降与纺丝均一性控制技术、高黏熔体大流量纺 丝技术、工业丝高倍多级牵伸与定型技术、工业丝 低能辐照表面活化技术等, 建立高性能工业丝质量 控制、检测标准及评价方法体系, 开发出具有高强 度、高模量、低干热收缩率的高性能工业丝。

\section{5. 土工建筑增强纤维}

以 PAN 纤维、聚乙烯醇纤维和聚丙烯土工材 料为重点, 突破高强度高模量聚乙烯醇纤维规模化 制备技术、高强高模与易分散聚丙烯腈纤维规模化 制备技术、高强抗老化粗旦聚丙烯纺粘针刺土工布 制备技术以及土工建筑增强用纺织品高效施工技术 等, 建立工程纤维纺织品服役与失效预警机制, 实 现土工建筑增强材料万吨级的应用示范。

\section{6. 高性能纤维}

对于碳纤维, 突破 M60J 级的中试技术, 实现 $\mathrm{M} 55 \mathrm{~J}$ 级的百吨级连续化稳定生产。对于对位芳纶, 提升产品质量、研发差异化的产品、建设万吨级智 能化生产线, 提升全球市场份额, 在国内市场的占 
有率超过 $80 \%$ 。对于 UHMWPE 纤维, 开发环保、 高效纺丝溶剂及创新生产路线, 研制高效、安全新 型设备, 实现更高性能 UHMWPE 纤维的规模生产。 对于 PI 纤维, 实现高强高模纤维强度达到 $4.2 \mathrm{GPa}$ 以上, 模量 $180 \mathrm{GPa}$, 在结构复合材料得到广泛应 用。对于 PPS 纤维, 纤维级 PPS 树脂的品质和成 本达到或超过国外领先企业; 实现 PPS 纤维的连续 纺丝, 并应用于产业化; 提高 PPS 纤维耐热和耐氧 化等性能，并拓宽应用市场。

\section{7. 生物基纤维}

对于莱赛尔纤维, 突破单线产能大于 $6 \times 10^{4} \mathrm{t} / \mathrm{a}$ 技术与装备, 突破新一代低成本抗原纤化技术与装 备, 产能达 $3 \times 10^{6} \mathrm{t} / \mathrm{a}$ 以上。对于聚乳酸纤维, 突破 丙交酯高效制备、提纯及产业化技术, 聚乳酸产能 达到 $3 \times 10^{5} \mathrm{t} / \mathrm{a}$ 左右。对于 PTT 纤维, 突破生物基 PTA 高效制备、提纯及产业化技术, 生物基 PTT 产能达到 $2 \times 10^{5} \mathrm{t} / \mathrm{a}$ 左右。

\section{（二）提升智能制造水平}

针对化学纤维材料领域, 不断提高智能制造水 平，在新一代纤维智能制造基础和支撑技术、纤维 智能制造新模式技术、智能纤维材料技术等方面实 现全面突破; 初步完善人工智能驱动和使能下的新 一代纤维智能制造平台体系，建成纤维产业智能制 造国家重点实验室，打造我国纤维产业智能制造科 技创新中心; 形成国际化的纤维智能制造工程科技 人才高地。预计到 2025 年我国纤维产业智能制造 技术总体水平达到国际先进。

加强纺织产业领域的智能制造技术研发和工程 化应用。以纺织产业智能制造标准、共性技术、装 备技术等为基础和支撑, 围绕纺织产业链布局, 发 展纺织制造智能车间 (工厂) 技术、大规模个性化 定制技术、网络化纺织制造和纺织装备远程运维等 纺织智能制造新模式技术。面向纺织产业智能化拓 展，布局发展智能纺织材料技术，构建纺织产业智 能制造技术体系。

建设纺织产业智能制造平台体系，布局建设 涵盖智能制造基础和支撑技术、智能制造新模式 技术、智能纺织材料技术等的纺织产业智能制造 国家重点实验室; 建设纺织产业智能制造标准和 共性技术国家工程技术研究中心; 构建面向纺织 各行业的纺织工业物联网和纺织产业大数据平台;
在纺织产业集聚区建设若干面向企业的纺织智能 制造云平台。

\section{（三）加强自主创新能力建设}

目前, 我国纤维材料产业科技创新体系不强、 不完整的矛盾突出, 产业发展存在的突出问题长期 未能有效解决, 具体表现为: 企业自主研发能力薄 弱, 产业关键共性技术供给不足, 面向中小企业的 技术创新服务严重缺乏，产业创新发展缺乏系统谋 划, 创新资源配置分散。对此, 需要加强以下工作。

(1) 完善国家纤维材料产业技术创新发展战略。 建议成立由政府相关部门、骨干企业、科研院所组 成的国家纤维产业技术创新战略委员会, 深入研究 产业技术创新战略、技术路线、发展规划, 提出政 策建议, 指导产业发展。

（2）建立国家级的纤维材料创新中心，布局国 家重点实验室和工程技术研究中心, 解决颠覆性、 竞争前技术创新能力薄弱的问题，占领科技制高点。

（3）纤维产业已建立的化纤产业技术创新战略 联盟和新一代纺织设备产业技术创新战略联盟已成 为引领和支撑纤维产业技术创新的新型组织。应进 一步发挥政府资源的引导作用，鼓励和支持这些联 盟优化运行机制、完善产业技术创新链。同时在高 性能纤维及其复合材料、生物基纤维材料等新兴领 域加快形成一批产业技术创新战略联盟, 围绕产业 链构建技术创新链。

（4）建设完善产业集聚区技术创新服务平台。 以地方政府和企业投入为主, 在长江三角洲、珠江 三角洲、福建等产业集聚区或工业园区建设完善专 业化的技术创新服务平台。政府通过政策优惠、购 买服务等方式, 支持平台为中小企业提供高效率、 低成本的专业化服务。

（5）支持骨干企业提升技术创新能力。在纤 维新材料重点品种、装备等领域, 支持骨干企业加 大科技投入、加强研发机构和研发体系建设、加大 “产、学、研” 合作, 增强企业自主创新能力。推 动有条件的骨干企业在全球范围内吸纳创新资源, 提升国际竞争力。

（6）完善材料应用技术评价和标准体系。建 立纤维材料标准实验室, 重点开发材料测试标准与 产品标准。建立产品应用技术评价中心, 通过规范 产品及其评价测试方法为市场应用推广和技术转移 
提供支撑, 促进纤维材料的产业化应用。突出材料 标准体系在产品创新工作中的基础性支撑和推动作 用, 提高标准国际化水平, 增强国际话语权。

\section{（四）加强科技人才队伍建设}

加强纤维产业工程科技领域及相关基础研究领 域的领军人才队伍建设, 加强纤维产业科技各领域 及方向的国家级创新团队建设; 建立规范制度, 加 强纤维企业技术人员及技术工人培训, 整体提高企 业人员素质, 转变知识能力结构; 发展纺织产业智 能制造技术方向的高等教育、高等职业技术教育及 中等职业技术教育, 培养多层次复合型纺织智能制 造专业人才; 同时, 在世界范围引进纤维新材料及 纤维科技基础研究高端人才。

\section{六、对策建议}

根据我国纤维产业发展的国内需求和国际竞争 状况, 针对先进纤维材料发展存在的突出问题, 提 出以下对策建议。

\section{（一）加强产业发展战略研究}

集聚科研、生产、规划研究、行业管理、金融 投资等专业人才, 建立一支结构合理、稳定的高水 平产业发展战略研究队伍, 针对先进化学纤维材料 产业发展中的科技创新、产融结合、现代产业链和 产业集群、产业转移与国际竞争等重要现实问题, 开展持续、深入的系统研究, 跟踪、评估发展状况 和规划实施情况, 及时调整、持续完善规划, 为我 国宏观决策，尤其是生产企业、金融投资机构、科 学研究机构等决策提供可靠的指导。

\section{（二）完善产业科技创新体系建设}

按照 “围绕产业链部署创新链、围绕创新链布 局产业链” 的总体要求, 完善国家、各部委重点实 验室的布局, 发挥实验室之间的协同机制, 部署纤 维材料与工程的重大科学问题研究; 加大政府资金 支持力度, 建立一支从事高水平基础研究的人才团 队, 产出一批原始创新成果; 发挥政府的引导和政 策保障作用, 吸引风险基金、产业基金, 提升工程 研究中心中试研究、工程研究能力, 优化创新成果
转化机制, 加快形成一批重大产业化技术成果; 支 持、鼓励产业技术创新战略联盟发挥在产业链协同 创新上的重要作用, 加快科技成果的市场应用; 支 持、鼓励中介服务机构不断提升服务能力和公信力, 在标准研制, 知识产权服务, 科技成果评估、转化, 品牌建设等方面发挥作用。

\section{（三）加强科学技术对产业发展的支撑和引领作用}

围绕产业基础高级化和产业链现代化全面部署 创新链, 重点在聚合物、纤维制造技术和装备领域, 整合行业重点实验室、工程中心和骨干企业的科技 资源, 围绕重点品种开展 “产学研” 合作, 确保重 点品种具有自主知识产权和持续的技术迭代升级能 力。围绕创新链布局产业链, 推动化学纤维产业基 金和风险投资, 加大对原始创新纤维品种开发与应 用的资金支持，占领科技制高点，培育优势产业。 推动工程公司向解决方案服务商转型发展, 通过 提高工程公司的科技研发、工程转化等综合能力, 创新经营模式, 整合科技资源, 构建全方位的产 业链、供应链管理服务模式, 建设高水平的科技 服务型企业。

\section{（四）支持骨干企业的国际化}

发达国家的经验表明, 大企业通过集聚 “产学 研” 创新资源、扩张重点品种的产能规模、延伸产 业链等, 占据了国际竞争的优势地位。当前, 我们 一些企业已具备了产能、经营管理、“产学研” 合 作等基础条件, 要积极支持此类企业延伸产业链、 全球布局产能和创新资源、加大 “产学研” 合作, 引导产业基金等社会资本投入，加快形成具有国 际竞争优势的跨国企业, 引领我国先进纤维材料 的产业发展。

\section{（五）材料、高端装备与智能制造的统筹发展}

顺应先进纤维材料与智能制造技术融合的发展 趋势, 促进先进纤维材料与高端装备融合发展, 突 破关键技术与装备, 推进国产装备与智能制造系统 的应用, 推动行业制造水平全面提升。加强智能化、 差异化、功能化设备及高新性能纤维设备的原创研 发能力, 增强重大技术与成套装备研发和产业化能 力, 提升产品附加值, 通过设备技术进步引领化学 
纤维产业的深度转型升级。加快突破化纤制造过程 的数字化、智能化关键技术，扩大国产装备与智能 制造系统在行业骨干企业中的应用，确保我国数据 和产业安全, 提升化学纤维产业的国际竞争力。

\section{参考文献}

[1] 端小平, 陈向玲, 戎中钰. 科技进步与化纤工业 [J]. 高分子通报, 2013 (10): 1-6.

Duan X P, Chen X L, Rong Z Y. Sci-technologiacal process and chemical fiber Industry [J]. Polymer Bulletin, 2013 (10): 1-6.

[2] 李雪梅, 薛孝川, 罗丽珊. 功能性纤维材料研究进展 [J]. 化纤与 纺织技术, 2015, 44 (4): 27-33.

Li X M, Xue X C, Luo L S. The advance and research progress of functional fiber materials [J]. Chemical Fiber \& Textile Technology, 2015, 44(4): 27-33.

[3] 中国化学纤维工业协会. 2020年中国化纤经济形势分析与预测
[R]. 北京: 中国化学纤维工业协会, 2020: 166-173.

China Chemical Fibers Association. Analysis and forecast of China chemical fiber's economy of 2020 [R]. Beijing: China Chemical Fibers Association, 2020: 166-173.

[4] 董奎勇, 杨婷婷, 王学利, 等. 生物基聚酯与聚酰胺纤维的研发 进展 [J]. 纺织学报, 2020, 41 (1): 174-183.

Dong K Y, Yang T T, Wang X L, et al. Research and development progress of bio-based polyester and polyamide fibers [J]. Journal of Textile Research, 2020, 41 (1): 174-183.

[5] 罗益锋. 新形势下高性能纤维与复合材料的主攻方向与新进展 [J]. 高科技纤维与应用, 2019 (5): 1-22.

Luo Y F. The main direction and new developments of high performance fibers and their composites in the new situation $[\mathrm{J}]$. HiTech Fiber and Application, 2019 (5): 1-22.

[6] 李增俊. 生物基化学纤维产业发展现状与展望 [J]. 生物工程学 报, 2016, 32(6): 775-785.

Li Z J. Development and perspective of bio-based chemical fiber industry [J]. Chinese Journal of Biotechnology, 2016, 32(6): 775785. 